\title{
PROCESSO DE DRAMA COMO POSSIBILIDADE ARTÍSTICO-PEDAGÓGICA NA EDUCAÇAO INFANTIL: DESCOBERTAS DE UMA PROFESSORA DE TEATRO EM FORMAÇÃO
}

Ohanna Simioni Picolo Pereira ${ }^{1}$

\section{Resumo}

Esta escrita discute minha experiência como aluna do curso de Licenciatura em Teatro pela Universidade do Estado de Santa Catarina (UDESC) e participante do Programa Institucional de Bolsas de Iniciação à Docência (PIBID). Apresento pontos específicos sobre a prática de encontro do teatro e da pedagogia exercida no Núcleo de Desenvolvimento Infantil (NDI) direcionando a um pensamento crítico sobre a ação educativa proposta pela experiência teatral onde o participante e/ou aluno pode ser estimulado a efetivar um ato produtivo, elaborando reflexivamente conhecimentos acerca de o próprio fazer artístico/teatral, quanto sobre aspectos relevantes da vida em sociedade.

Palavras-chave: Licenciatura em Teatro, Metodologia do drama, PIBID.

\section{DRAMA IN PROCESS AS ARTISTIC-PEDAGOGICAL POSSIBILITY IN CHILDHOOD EDUCATION: DISCOVERIES OF A THEATER TEACHER IN} TRAINING

\begin{abstract}
This dissertation discusses my experience as a student of the Theater course at the University of the State of Santa Catarina (UDESC) and participant in the Institutional Program of Initiatives for Teaching (PIBID). I present specific points about the practice of meeting the theater and pedagogy exercised in the Child Development Center (NDI) directing a critical thinking about the educational action proposed by the theatrical experience where the participant and/or student can be stimulated to carry out a productive act, elaborating reflexively knowledge about the artistic/theatrical doing itself, and about relevant aspects of life in society.
\end{abstract}

Keywords: Undergraduate of Theater, Process Drama, PIBID.

No ano de 2016, dentro do Programa Institucional de Bolsa de Iniciação à Docência (PIBID) da Universidade do Estado de Santa Catarina (UDESC) como graduanda do Curso de Licenciatura em Teatro, atuei na docência no Núcleo de

\footnotetext{
${ }^{1}$ Egressa do Programa de Pós-Graduação em Teatro (PPGT) da Universidade do Estado de Santa Catarina (UDESC); ohanna-picolo@hotmail.com
} 


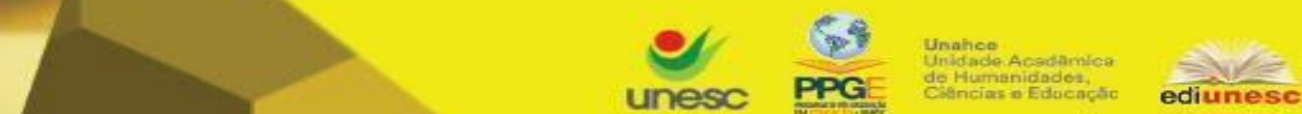

Criar Educação, Criciúma, v. 9, ㄲo2, Edição Especial 2020.- PPGE - UNESC - ISSN 2317-2452

Desenvolvimento Infantil (NDI) da Universidade Federal de Santa Catarina (UFSC) com a turma da Professora Margareth Cisne ${ }^{2}$. Este trabalho foi realizado juntamente com outra colega da graduação sob a orientação da Professora Vânia Broering ${ }^{3}$, a supervisora do PIBID na área de Teatro da UDESC e da Professora da turma, através desta parceria construímos uma ponte de estímulos para o desenvolvimento de um projeto criativo e sensível que foi realizado no NDI no último ano.

O projeto com os alunos da turma do $4 \% 5^{\circ}$ B percorreu diferentes fases e temáticas, que se desencadeou por uma premissa: $O$ interesse dos alunos por determinado assunto. O grupo de crianças estava em uma fase de seu desenvolvimento mobilizada pela grande curiosidade em relação aos objetos e atividades que envolvessem novidades quanto à: texturas, formatos, escutas, gostos, cheiros e cores. E foi assim que criamos um projeto baseado em atividades sensoriais. Deste modo, no decorrer do semestre, pautamos nossas propostas com o objetivo de vincular as atividades teatrais com materiais que estimulassem essas crianças, principalmente quanto ao sentido tátil.

Ao conhecer a turma e antes de desenvolver nosso projeto com os alunos, havíamos sido informadas sobre um projeto desenvolvido pelas professoras das turmas que visava misturar duas faixas etárias, quatro e cinco anos, para acompanhar como se desenvolvem as crianças dispostas desta maneira. Desta forma, foram pensadas maneiras de se trabalhar com ferramentas tanto pedagógicas como teatrais que visassem enriquecer e integrar o nosso trabalho com projeto de pesquisa, acima do projeto realizado pelas professoras naquele ano.

Nossas primeiras aulas eram baseadas em contação de histórias, utilizamos objetos, movimentos e ações que ilustrassem ainda mais a história, possibilitando às crianças o movimento de imersão imagética daquilo que estava sendo contado. Após a contação havia um espaço para a relação do aluno e os envolvidos com a história

2 Doutora em Educação pelo Programa de Pós Graduação em Educação da Universidade Federal de Santa Catarina (UFSC). Professora do Núcleo de Desenvolvimento Infantil (NDI).

${ }^{3}$ Graduada em Educação Artística na Universidade do Estado de Santa Catarina (UDESC) e especialização em Psicopedagogia pela Universidade do Sul de Santa Catarina (UNISUL). Supervisora do Programa de bolsas de Iniciação à Docência - Pibid - Capes, na área de Teatro na UDESC junto ao NDI. 


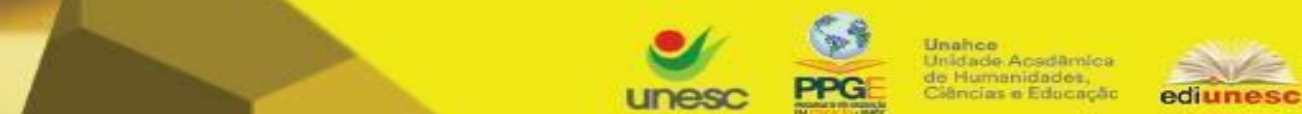

Criar Educação, Criciúma, v. 9, №2, Edição Especial 2020.- PPGE - UNESC - ISSN 2317-2452

contada, uma aproximação. O grupo demonstrou ter interesse em tocar em tudo que estava dentro da história, e com esse toque surgiu um convite para a imaginação, onde cada um reelaborasse uma própria história daquele material de ilustração o qual a criança estava segurando e se relacionando de alguma forma. Com esse o tocar, era possível perceber o movimento do vínculo entre o dado real (objeto) e a imaginação.

Ainda que lidando com crianças, um trecho do livro Pedagogia do Teatro: Provocação e dialogismo vai ao encontro da experiência de contação de histórias com a turma do $4 / 5 \mathrm{~B}$ :

Ouvir contação de histórias constitui-se, em vigorosa experiência pedagógica, à medida que compreende as tramas, reporta-se à própria existência; à medida que interpreta as histórias narradas, revê criticamente os aspectos de sua vida, tomando consciência da própria história, estando, assim, em condição de transformá-la. A experiência artística se coloca desse modo, como reveladora, ou transformadora, possibilitando a revisão crítica do passado, a modificação do presente e a projeção de um novo futuro. (DESGRANGES, 2010, p. 26).

A utilização de contações de histórias é uma prática comum na educação infantil, é uma estratégia didática de narração ao qual desencadeia curiosidades, comentários e temas de interesses. E as atividades dramáticas e sensoriais atuam como suporte neste período de formação do eu de cada criança. Vygotsky afirma que o "[...] pensamento da criança evolui em função do domínio dos meios sociais do pensamento, quer dizer, em função da linguagem" (VYGOTSKY, 1993, p. 116), a evolução do pensamento infantil estava no exercício de autoria e imaginação das crianças a partir de elementos e objetos dispostos na realidade, onde aqueles alunos eram autores de suas próprias histórias, eles remetiam a suas memórias pessoais que tal objeto ou artifício despertou e recontaram da sua maneira uma história sobre a peça que escolheram dar o protagonismo.

Outra atividade que despertou o interesse das crianças foi um caça tesouros com a temática de arco-íris, na qual as cores haviam fugido e estavam escondidas pelo espaço do NDI. Uma proposta que despertou mistérios, revelações e imaginação.

$A$ atividade do caça arco-íris, ainda que sem uma intenção inicial, era composto por elementos da metodologia do drama. O Drama é um método de ensino utilizado 


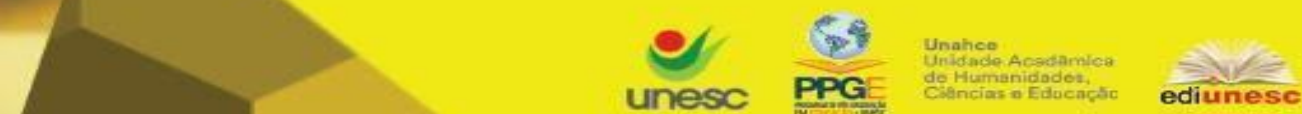

Criar Educação, Criciúma, v. 9, №2, Edição Especial 2020.- PPGE - UNESC - ISSN 2317-2452

por meio de construir uma história coletiva, onde todos são autores e não traz o protagonismo para alguém específico, é uma proposta de aquisição de conhecimento, não de técnicas cênicas. De acordo com a Professora Doutora que desenvolveu o método do drama no ensino do teatro no Brasil, Beatriz Angela Cabral (2006, p.11) "Drama é uma atividade criativa em grupo, na qual os participantes se comportam como se estivessem em outra situação ou lugar, sendo eles próprios ou outras pessoas".

Estar inserida no processo de drama como mediadora nas atividades foi um grande desafio, na qual a premissa era guiada por buscar uma posição de disponibilidade para a interação com os alunos, sistematizar o envio dos estímulos para as crianças e receber de volta os estímulos que elas me enviaram, tendo a sensibilidade de articular a gama de imaginação que percorre nessas atividades sem desviar o foco da proposta do exercício daquele dia.

Com o passar dos meses a ideia do processo de drama foi se fortificando como possibilidade e no segundo semestre do ano iniciamos com uma temática efervescente dentro da turma: o espaço sideral. Aos meus olhos como educadora, uma possibilidade temática fantástica para aprofundar questões lúdicas, sensoriais e científicas naquela proposta. Intitulou-se este processo de drama como $A$ viagem espacial, onde a cada encontro, o grupo de alunos deveria cumprir uma determinada missão para poder viajar para o espaço, na metodologia do drama nossos encontros passaram a ser chamados de episódios.

O processo se dá em episódios, como são chamados os encontros dos grupos, nesses episódios, todos são participantes, sem nenhum tipo de audiência, incluindo o professor que pode se integrar ao contexto como professor personagem, um mediador da trama, elemento de apoio ao pré-texto e à concepção da história. Heloise Vidor resumiu essas características da seguinte forma:

Dentre as características principais do drama estão: contexto e circunstância de ficção que tenham alguma ressonância com a realidade dos participantes, processo desenvolvido através de episódios guiados por um pré-texto, que configure a narrativa, mediação de um professor-personagem, que permite focalizar a situação sob perspectivas e obstáculos diversos (VIDOR, 2010, p. 29). 
Algo que despertou a nossa atenção foi a forte presença do objeto mochila a jato, que surgiu de um aluno, quando questionado o que ele levaria para lua e este foi seu objeto escolhido, então buscamos referências do objeto de modo que poderíamos construir mochila a jato com materiais comuns como garrafa pet, papel alumínio e fitas coloridas. Inserir objetos citados pelos alunos é um dos grandes presentes que o processo de drama proporciona ao educador.

Acredito que uma das etapas mais desafiadoras neste processo foi ter que, além de estar receptiva e perceptiva em tempo real aos estímulos que o processo de drama propõe, foi ter que lidar com a confusão do real e ficcional que as crianças inevitavelmente questionavam em determinados momentos e isso era passado pra mim como mediadora do processo. Busquei sempre rebater com novas perguntas a cada pergunta que eu recebia e deixar com que cada aluno formulasse seu pensamento próprio acima do enigma que é participar de um processo de drama, principalmente na infância. Diego de Medeiros Pereira nos lembra neste trecho:

Independente de qual seja o objetivo para a instauração de um processo de Drama, é importante frisar que a essência desse trabalho encontra-se no ato do participante experimentar estar em "outro" tempo e espaço, vivenciando diferentes papéis dentro do contexto ficcional criado; e, neste sentido, Drama e Teatro possuem a mesma essência, a experiência dramática de fazer de conta (PEREIRA, 2014, p. 5).

Procurei levar em consideração todos os apontamentos dos alunos a cada episódio desenrolado e dos feedbacks mesmo que em detalhes, para transformar num novo gatilho para o próximo episódio. Foi de grande importância que os estímulos partissem do grupo inserido no drama e no papel de mediadora, interferir menos e organizar a articular as temáticas valiosas que o grupo de crianças emitia.

Com toda certeza, a parceria e orientação de professores em formação com a equipe de educadores em exercício proporciona ao aluno de Licenciatura uma experiência no ambiente escolar que jamais poderia ser adquirida em sala de aula nas Universidades, a verdadeira formação de professores está nas relações entre o campo de formação e o campo profissional, quanto mais próxima e intensa se dá esta relação, mais qualificada torna-se a atuação do professor. O PIBID proporcionou o 


\section{CRIAR EDUCAÇÃO}

Revista do Programa de Pós-Graduação em Educação - UNESC

Criar Educação, Criciúma, v. 9, n²2, Edição Especial 2020.- PPGE - UNESC - ISSN 2317-2452

contato com essa realidade antes da conclusão do Curso e foi por meio da liberdade no planejamento das intervenções didáticas propiciadas às crianças que o diálogo com a realidade foi possível, somado a esse privilégio, a presença e o interesse das profissionais e educadoras envolvidas com os suportes constantes a cada atividade realizada com a turma.

\section{Referências}

CABRAL, Beatriz. Drama como método de ensino. São Paulo: Hucitec, 2006.

DESGRANGES, Flávio. A pedagogia do Teatro: provocação e dialogismo. São Paulo: Editora Hucitec: Edições Mandacaru, 2010.

PEREIRA, D. M.. Teatro na Educação Infantil: em busca de possibilidades. In: X ANPED SUL, 2014, Florianópolis. Trabalhos completos X ANPED Sul, 2014.

VIDOR, Heloise Baurich. Drama e Teatralidade: o ensino do teatro na escola. Porto Alegre: Mediação, 2010.

VYGOTSKY, L. S. Pensamento e Linguagem. São Paulo: Martins Fonte, 1993.

Recebido fevereiro de 2018 Aprovado junho de 2020 